\title{
MAKNA GERAK TORTOR MANGONDAS DALAM UPACARA KEMATIAN SAUR MATUA PADA MASYARAKAT BATAK TOBA DI KABUPATEN SAMOSIR
}

\author{
RINDA TURNIP \\ Prodi Pendidikan Tari
}

\begin{abstract}
Tortor Mangondas is an expression of sorrow that was created to meet the needs of indigenous meaningful honor the dead (and of the spirit / tondi man and tondi the first death) and is a communication between the real world and the other world (deceased) for application of this world can be given to the fathers and good luck / blessing of them can be given to people who live mainly heirs. This study aims to find out what the meaning contained in Tortor Mangondas in Toba Batak society.

The theoretical foundation of this research uses one theory, the theory of meaning and understanding tortor mangondas and death ceremonies.

Location and time the research was conducted in Samosir and time for two months, the sample population figures there are some dancers and artists as well as traditional leaders. The author conducted field observations, with video capture, documentation, and conduct interviews with sources, as well as complete the data through research at the Village Siopat bill Samosir

The results based on the data that has been collected can be seen that Tortor Mangondas never appears solely as a form of dance in any society. But the motion-motion can still be explained the meaning of each movement performed. Tortor Mangondas created because someone who has died Saur matua not have a chance to talk to the family to deliver the parting words and all expressions hearts content. The social value as a society Batak Toba Mate Saur Matua whereby Tortor Mangondashasuhutan held with the objective of respect for parents and at the same time submit a request to Mulajadi Nabolon prayer.
\end{abstract}

Keywords: Meaning, Tortor Mangondas, death ceremony, Saur Matua 


\section{PENDAHULUAN}

Kabupaten

Samosir

merupakan salah satu kabupaten baru

di Provinsi Sumatera Utara dengan

wilayah administrasi pemerintahan

sebanyak sembilan kecamatan dan

seratus sebelas desa serta enam

kelurahan dengan batas-batas

wilayah sebelah Utara berbatasan

dengan Kabupaten Karo dan

Kabupaten Simalungun, sebelah

Selatan berbatasan dengan

Kabupaten Tapanuli Utara dan

Kabupaten Humbang Hasundutan,

sebelah Timur berbatasan dengan

Kabupaten Toba Samosir, sebelah

Barat berbatasan dengan Kabupaten

Dairi dan Kabupaten Pakpak Barat

(Sibarani,Sadar 2006:1).Kematian

merupakan akhir dari perjalanan

hidup manusia. Seseorang disebut

Saur matua, ketika meninggal dunia

dalam posisi "Titir Maranak, titir
Marboru, marpahompu sian anak, marpahompu sian boru" (anak lakilaki dan perempuan sudah menikah dan memiliki cucu dari anak perempuan dan laki-laki). Tetapi sebagai umat beragama, hagabeon (kesejahteraan karena berketurunan), belum tentu dimiliki seseorang. Hagabeon merupakan kehormatan karena lengkapnya keturunan. Anakanaknya yang sudah menikah juga sudah melakukan adat yang penuh atau mangadati. Jadi tidak sembarangan untuk masuk kedalam saur matua. Saur matua disebut juga dengan acara sampe tua dan sahat matua.

Tortor Mangondas adalah suatu ekspresi dukacita yang diciptakan untuk memenuhi kebutuhan adat yang bermakna menghormati yang meninggal (serta roh/ tondi orang itu dan tondi yang 
duluan meninggal) dan merupakan sebagai komunikasi antara dunia nyata dan dunia lain(yang sudah meninggal) agar permohonan dari dunia ini dapat diberikan kepada nenek moyang dan tuah/ berkat dari mereka dapat diberikan kepada orang yang hidup terutama ahli warisnya.

Tortor Mangondas diadakan terhadap saur matua (na gabe) dimana dia telah memiliki cucu dari anak laki-laki dan cucu dari anak perempuan. Tortor Mangondas salah satu bentuk pelestarian budaya dan bentuk kesenian yang ada pada masyarakat Batak Toba yang menjadi fokus penelitian membuat penulis merasa tertarik untuk mengangkat tarian ini menjadi topik penelitian dengan judul "Makna gerak Tortor Mangondas dalam Upacara Kematian Saur Matua pada masyarakat Batak Toba di Kabupaten Samosir".

\section{Landasan Teoritis}

Untuk membahas Tortor Mangondas dalam Upacara Kematian Saur Matua pada Masyarakat Batak Toba di Kabupaten Samosir penulis menggunakan teori makna dari Curt Sachs dalam Anya Peterson Royce terjemahan F.X Widaryanto (2007:213-22).

\section{Lokasi Penelitian}

Tempat dilaksanakannya penelitian adalah di Desa Siopat Sosor Kecamatan Pangururan.

\section{Populasi dan Sampel}

Populasi

Populasi dalam penelitian ini, adalah penari dan beberapa tokoh seniman dan tokoh adat yang 
mengetahui tentang Tortor prosedur pemecahan masalah yang Mangondas yang berdomisili di diselidiki dengan menggambarkan Kabupaten Samosir.

keadaan objek penelitian pada saat sekarang Kabupaten Samosir. Sampel

Sampel dalam penelitian ini Waktu yang digunakan dalam penelitian ini untuk mendapatkan berjumlah 4 orang tokoh adat dan seniman yang ada di kabupaten Samosir

\section{Teknik Pengumpulan Data} data dibutuhkan adalah selama tiga bulan yang akan dilaksanakan pada November 2015 sampai Februari 2016.

Teknik pengumpulan data yang dilakukan sebagai berikut :

\section{Letak Geografis Kabupaten}

\section{Samosir}

1. Observasi

Letak Geografis Kabupaten

2. Wawancara

3. Kepustakaan

4. Dokumentasi

5. Studi kepustakaan

\section{Teknik Analisis Data}

Penulis menganalisis dan menguraikan data-data tersebutdengan menggunakan penelitiankualitatif yaitu sebagai

Samosir terletak pada $2024^{6}-20$ $25^{`}$ Lintang Utara dan $98021^{\prime}$ - 990

55 $\quad$ BT. Secara Administratif Wilayah Kabupaten Samosir diapit oleh tujuh Kabupaten, yaitu di sebelah Utara berbatasan dengan Kabupaten Karo dan Kabupaten Simalungun; di sebelah Timur berbatasan dengan Kabupaten Toba Samosir; di sebelah Selatan 
berbatasan dengan Kabupaten

Tapanuli Utara dan Kabupaten

Humbang Hasundutan; dan di

sebelah Barat berbatasan dengan

Kabupaten Dairi dan Kabupaten

Pakpak Barat.

Kabupaten Samosir terletak

di wilayah dataran tinggi, dengan ketinggian antara $904-2.157$ meter di atas permukaan laut, dengan topografi tanah yang beraneka ragam yaitu datar, landai, miring dan terjal. Struktur tanahnya labil dan berada pada wilayah gempa tektonik dan vulkanik. Kabupaten Samosir tergolong ke dalam daerah beriklim tropis basah dengan suhu berkisar antara 17 OC - 29 0C dan rata-rata kelembapan udara 85,04 persen.

Wilayah Kabupaten Samosir luas wilayah Kabupaten Samosir secara keseluruhan mencapai 254.715 Ha, terdiri dari daratan seluas 144.455 Ha dan perairan danau seluas 110.260 Ha. Luas dan batas perairan di kawasan danau Toba belum ada ketentuan yang pasti. Namun mengingat Pulau Samosir tepat berada dan dikelilingi oleh Danau Toba, secara proporsional luas perairan Danau Toba yang menjadi bahagian daerah Kabupaten Samosir (sumber : Badan Pusat Statistik Samosir).

Mata Pencaharian dan Sumber Daya Alam

Mata pencaharian Masyarakat Batak Toba adalah sebagai petani rumah, martonun (menenun ulos), nelayan.

Tahapan Pelaksanaan Upacara Adat Kematian Saur Matua

Pelaksanaan Upacara Adat kematian saur matua biasanya dilakukan berhari-hari dan paling 
cepat minimal tiga hari karena seseorang yang mati saurmatua adalah orang yang lanjut usia dan dengan demikian anaknya tidak berada dalam satu tempat. Untuk menunggu anak-anaknya pulang dari perantauan pelaksanaan upacara adat dilakukan berhari-hari maka dilaksanakanlah upacara penguburan.

Mangalap Pande Dohot Pargonsi

Mangondas

a. Pra Adat

b. Pelaksanaan adat

Mompo-Ulos saput-Ulos Sampe Tua

a. Sanggul Marata

Tortor Mangondas

\section{Ragam gerak}

1. Mangondasi

2. Mangondas disimanjujung

3. Mangondas disiubeon

4. Mangondas disimanjojak

5. Mangondas disitangkingon
6. Mambuat Tua/mangait tua tu siambirang

7. Mambuat Tua/mangait tua tu siamun

8. Somba Debata Mulajadi Nabolon

9. Somba diraja

10. Massiuk

11. Manjujung harajaon

12. Mangalap

tondini namate/mangalap sahala ni na mate

13. Mangait tua Demban tiar

14. Penghormatan terakhir

\section{Makna Gerak}

Tortor mangondas tidak pernah nampak terjadinya sematamata bermakna sebuah bentuk tari dalam masyarakat Batak Toba. Tetapi gerak-geraknya masih bisa dijelaskan makna dari setiap gerak yang dilakukan. Biarpun tidak sama gerak peran hula-hula, dongan tubu, 
boru tetapi ketiga dalihan natolu ini setidaknya melakukan ragam gerak tersebut. Ragam gerak dibawah ini ada dalam saat tortor mangondas meskipun tidak secara berurutan.

\section{PENUTUP}

\section{Kesimpulan}

Dari semua yang sudah diteliti di lapangan, dapat diambil kesimpulan bahwa kematian saur matua, merupakan sebuah upacara adat yang dilakukan oleh masyarakat Batak toba, ketika mereka mendapat kemalangan dengan meninggalnya orangtua mereka yang sudah menyelesaikan tugas duniawinya mengurus anak-anaknya. Di dalam pelaksanaan upacara banyak hal-hal yang harus diperhatikan dan dipersiapkan agar jalannya upacara, dan tujuan dari upacara itu sendiri akan mendapat jawaban dari Tuhan Debata Mula jadi nabolon.
Berdasarkanuraian yang sudahdipaparkandapatdiketahuibahw a:

1. Upacara saurmatuaadalah salah satu kegiatan dalam upacara adat untuk kematian bagi masyarakat Batak Toba. Upacara ini dilakukan apabila kematian yang terjadi pada orang tua yang sudah uzurusianya, dimana anak-anak seluruhnya sudah berumah tangga dan juga seluruhnya sudah mempunyai keturunan.

2. Ada 8 macam jenis kematian dalam masyarakat Batak Toba mulai yang terendah yaitu: 1) Mate di Bortian, 2) Mate Posoposo, 3) Mate Dakdanak, 4) Mate Bulung, 5) Mate Pupur atau Mate Ponggol, 6) Mate Punu Mate di Paralangalangan, 7) Mate Mangkar, 8) 
Mate Hatungganeon, 9) Mate

Sarimatua, 10) Mate

Saurmatua, 11) Mate Mauli

\section{Bulung}

3. Tortor Mangondas adalah suatu ekspresi dukacita yang diciptakan untuk memenuhi kebutuhan adat yang bermakna menghormati yang meninggal (serta roh/tondi orang itu dan tondi yang duluan meninggal) dan merupakan sebagai komunikasi antara dunia ini dan dunia lain ( yang sudah meninggal) agar permohonan dari dunia ini dapat diberikan kepada nenek moyang dan tuah/berkat dari mereka dapat diberikan kepada orang yang hidup terutama ahli warisnya.

4. Tortor mangondas tidak pernah nampak terjadinya sematamata bermakna sebuah bentuk tari dalam masyarakat Batak Toba. Tetapi gerak-geraknya masih bisa dijelaskan, makna dari setiap gerak yang dilakukan.

\section{Saran}

\section{Dari}

beberapakesimpulanhasilpenelitianda npembahasan, makadapatdiajukan saran-saran sebagaiberikut:

1. Melihat makna gerak TortorMangondasdalamUpacar a Kematian Saur Matuapada masyarakat Batak Toba memiliki peran yang sangat penting, diharapkan tradisi ini tetap dilaksanakan sebagai salah satu identitas seni budaya pada masyarakat Batak Toba.

2. Melihat pengaruh dan dampak perkembangan zaman yang begitu deras yang dapat mempengaruhi generasi muda 
untuk berpaling dari tradisi seni budayanya, perlu melakukan pembinaan untuk generasi muda. Generasi muda diharapkan dapat menggali/meneruskan tradisi Batak Toba supaya tidak punah, dan tradisi Batak Toba tersebut dapat diorbitkan.

3. Tortor Mangondas artinya prinsip untuk menghormati orangtua agar anak (pinompar) yang ditinggalkan mendapat umur yang panjang dan menerima berkat serta rejeki yang berlimpah, maka diharapkan generasi muda dapat meneruskan dan melestarikan serta mempertahankan adanya makna gerak TortorMangondas, misalnya mempelajari gerakannya, dan melihat keberadaan

TortorMangondasdalam

Upacara Kematian Saur Matuapada masyarakat Batak Toba.

4. Kepadaparaseniman, khususnyasenimanBatak Toba agar terusberkaryadanmenjagautuh kesenian tradisi Batak Toba.

5. Penulis sangat mengharapkan dukungan dari instansi terkait, agar ikut peduli terhadap tradisi-tradisi budaya Batak Toba demi melestarikannya. 


\section{DAFTAR PUSTAKA}

Anya, Peterson. 2007. Antropologi

Tari. Terjemahan F.X

Widaryanto. Bandung: STSI Press.

Burhan Bungin.2010.Penelitian kualitatifJakarta:Kencana

Debora, Ester. 2012. Gondang Sabangunan pada Tortor Sigale-gale di Desa Tomok Kecamatan Simanindo Kabupaten Samosir. Skripsi. Universitas Negeri Medan : Medan.

Fernandus, 2011. Struktur Tortor dalam Upacara Pernikahan Maasyarakat Batak Toba di Kecamatan Siborong-borong. Skripsi. Universitas Negeri Medan : Medan.

Hadeli. 2006. Metode Penelitian Kependidikan. Padang : Quantum Teaching.

Langer, Suzane K. 2006, Problema Seni. Ter. F. X. Widaryant, Bandung: STSI PMSS.

Koerantjraningrat, 2004. Kebudayaan, Mentalitas dan Pembangunan. Jakarta : Gramedia Pustaka Utama.

Manik Krisman.2012"Eksistensi Sarune Bolon dalam pelaksanaan adat Saur
Matua pada masyarakat batak Toba di desa bangun I kecamatan Parbuluan Kabupaten Dairi "Medan : Universitas Negeri Medan.

Nurwani. 2007. Pengetahuan Tari, Diktat Jurusan Sendratasik, FBS Universitas Negeri Medan.

Sihaloho, Nuriana, S, 2015. Penyajian Tortor dalam Upacara Pajonjong Baringin pada Masyarakat Batak Toba"Medan : Universitas Negeri Medan.

Purba, Mauly. 2012. Mengenal Tradisi Gondang dan Tortor Batak Toba. Medan : Universitas Sumatera Utara.

Siagian, Afriyanti. 2010. MaknaTortorsibungaJambudalamGo ndangNaposo padaMasyarakat Batak

Toba.Medan.UniversitasNegeriMeda $\mathrm{n}$

Sibarani, Sadar, 2006, Raja Batak, Jakarta : Partano Bato.

Simarmata, Golda, 2013. "Husiphusip dalam tortor Hatasopisik pada masyarakat Toba kajian Interaksi Simbolik"Medan : Universitas Negeri Medan. 
Soedarsono, 1987. Tari-tari

Indonesia. Jakarta

Direktorat Jenderal

Kebudayaan.

DAFTAR ACUAN INTERNET

http

//id.wikipedia.org/wiki/Tortor

Batak_Toba

Sukardi.

2003.MetodologiPenelitianKe

http://www.samosirkab.go.id/

pendidikan. Jakarta:

BumiAksara.

https://balarmedan.wordpress.com/20

$\underline{\text { 08/06/18/upacara-saur-matua- }}$

Tambunan,Betty.2008.Perkembanga konsep\%E2\%80\%9Dkematian-

$n$ Tortor Batak Toba ideal\%E2\%80\%9D-pada-

Tinjauan Terhadap Fungsi masyarakat-batak-studidan Bentuk Penyajian. Skripsi. Universitas Negeri Medan : Medan

etnoarkeologi/

http://www.hetanews.com/article/364 /saur-matua-dan-kematian-dalamadat-batak

https://www.google.com/search?q=m akna+dari+manjalo+tua+ni+g ondang+pada+upacara+kemat ian+saur+matua\&ie=utf$8 \&$ oe $=$ utf$8 \&$ aq $=$ t\&rls $=$ org.mozilla:enUS:official\&client=firefoxbeta\&channel $=n p \&$ source $=h p$ https://pungsin.wordpress.co m/tag/adat-saur-matua/ 